\title{
Unified Analysis of Road Pavement Profiles for Evaluation of Surface Characteristics
}

\author{
Giuseppe Loprencipe ${ }^{1} \&$ Giuseppe Cantisani ${ }^{1}$ \\ ${ }^{1}$ Department of Civil, Constructional and Environmental Engineeering, Sapienza, Università di Roma, Rome, \\ Italy
}

Correspondence: Giuseppe Loprencipe, Department of Civil, Constructional and Environmental Engineeering, Sapienza, Università di Roma, Rome, Italy. Tel: 39-6-4458-5112. E-mail: giuseppe.loprencipe@uniroma1.it

Received: May 22, 2013

doi:10.5539/mas.v7n8p1

\author{
Accepted: June 19, 2013 Online Published: July 5, 2013 \\ URL: http://dx.doi.org/10.5539/mas.v7n8p1
}

\begin{abstract}
The research deals with the measure and evaluation of the unevenness and texture of road pavements, by means of unified procedures both for surveys and processing of acquired data, with the aim to represent the surface characteristics as a spectrum in the domain of spatial frequencies (or wavelengths). The texture properties, in fact, can be referred to many aspects of pavements performances, so allowing to establish thresholds for the acceptability of new construction or to ensure good working conditions for existing road infrastructures.

The advantages of the proposed unified procedures are that the measurements are taken with modern and advanced equipment, minimizing the impact on the normal road exercise; moreover, it is possible to propose an optimized area in the frequency vs. texture level graph, where the spectrum has to fall into, in order to balance some conflicting requirements. The boundaries of the area can be also referred to the specific characteristics of the examined infrastructures; if a spectrum fits into the area, an optimal behaviour of the surface is ensured, respect to the interaction phenomena between tires and pavement which are influenced by surface texture.

The proposal was tested with a case study, in which thresholds of performance parameters and boundaries of the optimized area were decided onto the basis of correlations between road indexes and texture properties, coming from the scientific literature or proposed on the basis of empirical results.
\end{abstract}

Keywords: road pavements, texture, unevenness, analysis of frequencies, surveys, acceptance thresholds

\section{Introduction}

\subsection{Pavement Surface and Road Performances}

The interactions between road pavement and vehicle tyres influence many factors, directly or indirectly related to safety and efficiency of road exercise. Various characteristics of road pavements have importance for these problems, but a primary role is reserved to the surface geometry. A road pavement, in fact, can be realized in different ways and using various materials, but in every case its surface is never perfectly flat, even and smooth. It is important to know in detail the characteristics of surface, in order to evaluate and to ensure the related functional performances (Henry \& Dahir, 1979; Davis, 2001; Stroup-Gardiner et al., 2001).

For this purposes, the geometry of a paved road surface is usually described by means of specific characteristics or properties, like the "texture", the "unevenness" or the "roughness" and the National and International Agencies provide methods and standard for their determination (ASTM/E965, 1996); these characteristics are generally evaluated along linear profiles on the road surface (ISO13473-1:1997), considering some alignments on the pavement, for example according to the longitudinal or the transversal direction.

The texture, in particular, is defined as "the deviation of a pavement surface from a true planar surface" (ISO13473-1:1997); similarly, the roughness (that is the most common manner to indicate the unevenness of a road surface, in a macroscopic scale) is defined as the vertical variation of the distance of real points of the pavement, along a profile, from an ideal reference plane (Sayers \& Karamihas, 1998). It appears clear that the difference between the two cited properties is essentially due to the extension of the considered part of the pavement and to the wavelength and dimension of the gaps between the pavement and the ideal reference plan. In this sense, in the following of this paper, we will refer to the "texture" or to the "unevenness", meaning and including the entire domain of practical interest. 
In fact, both technical organizations (PIARC, 1987) and authors (Descornet, 1989) classify the roads surface characteristics, referring to the wavelength $(\lambda)$ of the irregularities, so defining four basic classes as a function of the domains of texture wavelengths (or, that is the same, according to the spatial frequency $f$, because the relation $f=1 / \lambda)$ : this classification is shown in the Figure 1 .

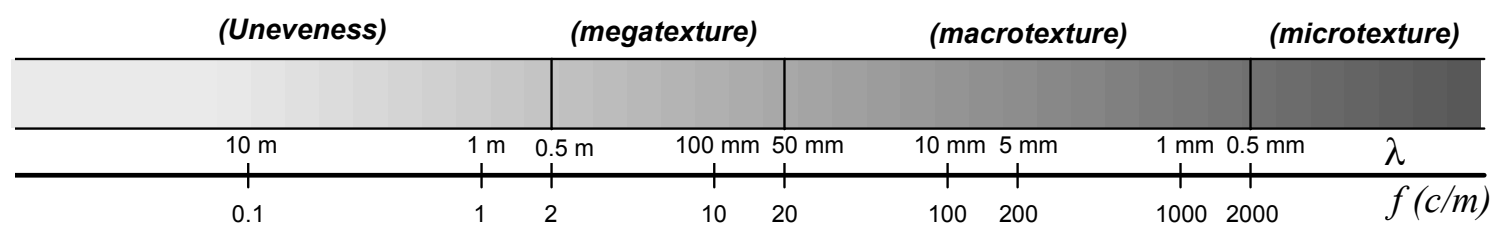

Figure 1. Definition of fundamental texture classes, as a function of the wavelengths or the spatial frequencies

Among the most significant properties of a road pavement, affected by the surface texture, it is important to consider: friction, drainage, noise, brightness, wearing, comfort, and so on. Moreover, the interaction phenomena depend on the exercise conditions (speed, dimensions, masses and suspension of vehicles, road characteristics, environmental conditions, etc.) and, again, on the wavelengths of the unevenness.

A proposal for the identification of relationships between fields of texture wavelengths and interaction phenomena was presented by the World Road Association (PIARC, 1987), as showed in the Table 1.

Table 1. Fields of texture wavelength and related interaction phenomena (PIARC, 1987)

PROPOSED CLASSIFICATION OD IRREGULARITIES ON ROAD PAVEMENT SURFACE

\begin{tabular}{llll} 
AREA & RANGE OF DIMENSIONS & IRREGULARITIES CONNECTED WITH & IRREGULARITIES HAVE AN INFLUENCE ON \\
\hline MICROTEXTURE & $\lambda<0.5 \mathrm{~mm}$ & $\begin{array}{l}\text { - Surface texture of each aggregate depending on } \\
\text { (particle) shape and angularity, texture of } \\
\text { bituminous and cement mortar, surface texture of } \\
\text { paving and setts and rock slabs, edges of grooves in } \\
\text { concrete slabs (saving or brushing treatment) }\end{array}$ & $\begin{array}{l}\text { - Skid-resistance (at all speeds) on wet pavement } \\
\text { and frequency tyre/pavement rumbling noise (inside }\end{array}$ \\
& & &
\end{tabular}

$\begin{array}{llll} & \text { - Mix design: aggregate particle size, shape, spacing } & \text { - Skid-resistance at medium to high speed on wet } \\ & \text { and arrangement } & \text { pavement }\end{array}$

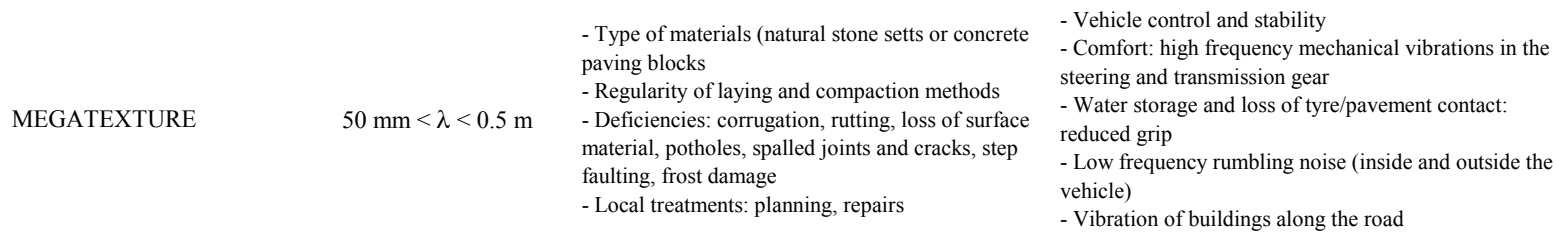

EVENNES

(SHORT

- Quality of laying of the materials (spreading and compaction)

- Pavement deterioration by traffic: subsidence, depressions with or without crazing - Frost damage

- Loss of tyre(pavement contact, reduced steerability and grip (even on dry pavement)

WAVELENGHTS) 
It is easy to observe that the above listed interaction effects determine some functional performances of the pavements that are related to the correct and reliable use of road infrastructures, especially in terms of users' safety and comfort. For this reason, it is important to be able to determine or measure the geometric conditions of a road surface, in order to accurately develop the design and construction activities as well as to plan and realize the most appropriate pavement management programs, when the infrastructures are subjected to the wear due to traffic and environmental actions.

\subsection{Texture and Unevenness as Global Indicators of Pavement Performance}

The interest of texture characterization, as an indicator related to the main functional pavement performances, is particularly highlighted because this parameter is easy to be measured and it is independent on local and environmental effects. Its determination, in effect, depends exclusively on geometric properties of the surface, so it is invariant respect to temperature, presence of water or other contaminants on the pavement, chemical modifications of materials, etc.

In addition the texture is a property related, in different way, to some conflicting performances of a pavement (Hibbs \& Larson, 1996; Baran \& Henry, 1983); in this sense, in fact, it is important to have an high texture level in order to maximize some functions (friction, vehicle control, prevention of aquaplaning) (Flintsch et al., 2012; Hall et al., 2009), whereas considering other requirements (noise, tyres and fuel wearing, comfort), it is better to have a low texture level (Rasmussen et al., 2007).

A synthetic representation of the quali-quantitative effects of texture and unevenness on pavement performances, in terms of good or bad influence on them, also considering the different wavelengths, was proposed by PIARC and can be explained by means of the graph reproduced in Figure 2 .

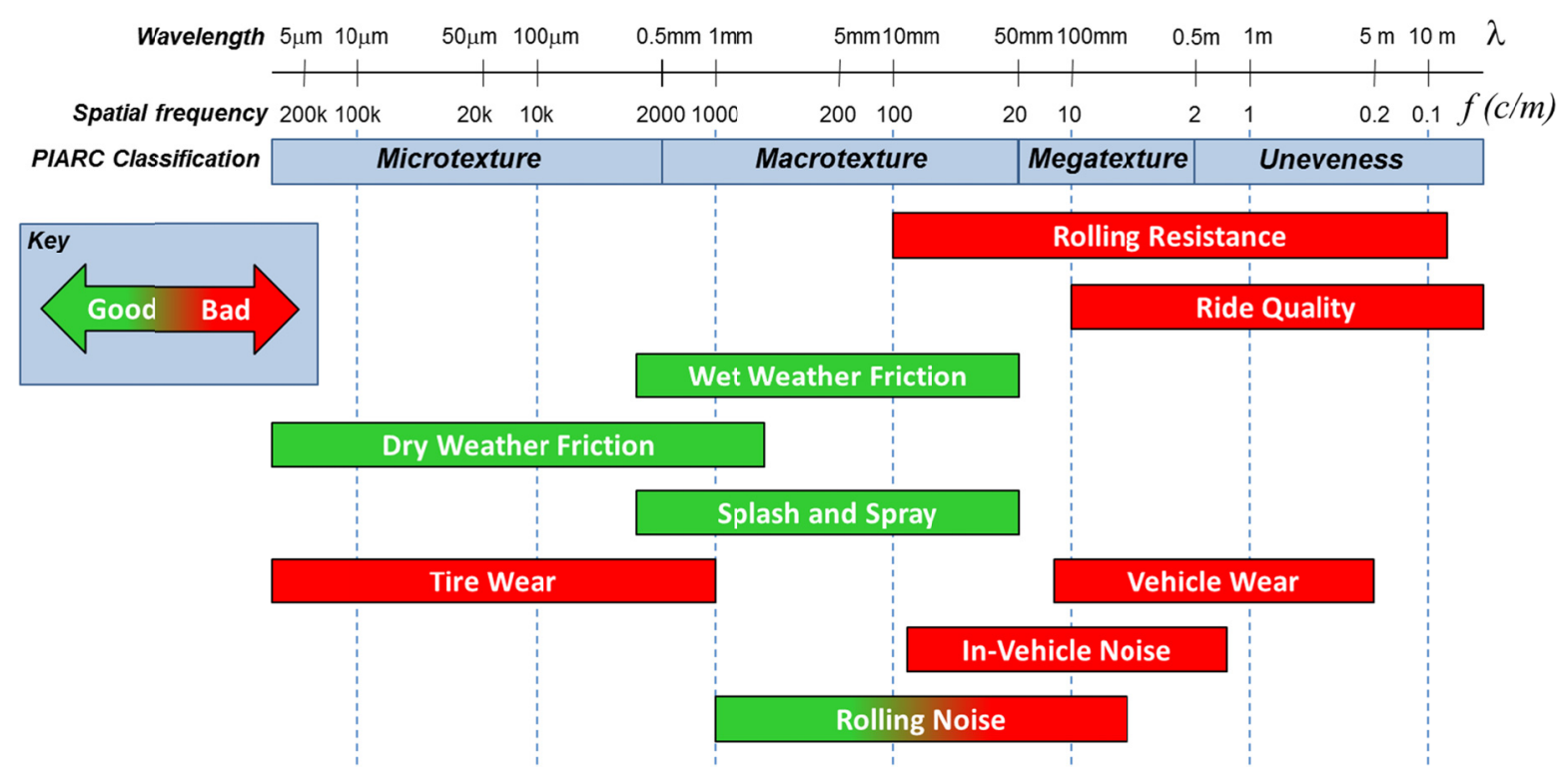

Figure 2. Pavement surface characteristic influence (Bitelli et al., 2012; Wambold et al., 1995)

In consequence of that, it seems useful to refer to the texture and unevenness all road surface properties, so obtaining the needed information to evaluate a pavement surface with a global representation. In other words, if an unique representative parameter for texture could be defined, it is possible to establish some thresholds, referred to this indicator (as maximum and minimum level) for each wavelength field, in order to obtain a pavement which allows to balance the opposite performances of a road infrastructure (Alauddin \& Tighe, 2008).

Nevertheless, for these aims, a difficulty rises because the traditional methods and techniques used to measure and evaluate the surface characteristics present many differences and particularities, in dependence of the extension of the surface to observe and the functional evaluation to perform. Furthermore, it is possible that the measures could be not fully representative of the real condition of the pavement, in reference to all the functional parameters that have to be determined. However, the recent developments of measurement and evaluation methods, allow to take on the described problem with a global and unified approach. 


\section{Methods for Measurements, Analysis and Evaluation}

Road management Agencies periodically measure the pavement surface characteristics, with different methods and equipment, in order to verify the acceptance respect to limit values (target, alert, threshold, etc.). The methods and equipment available may be one or more for each measured performance. Table 2 summarizes the commonly used measurement equipment for the pavement characteristics with the related technical standard.

Table 2. Examples of equipment for the measure of pavement performances

\begin{tabular}{|c|c|c|c|c|}
\hline Pavement characteristic & Example of equipment & $\begin{array}{c}\text { Discrete/ } \\
\text { Continuous }\end{array}$ & Standard & $\begin{array}{l}\text { Related Texture } \\
\text { Pavement }\end{array}$ \\
\hline \multirow{4}{*}{$\begin{array}{l}\text { Skid resistence/friction } \\
\text { (Funtional - safety) }\end{array}$} & Pendulum test (Portable tester) & Discrete & EN 13036-4 & micro \\
\hline & $\begin{array}{l}\text { Side-way force coefficient routine } \\
\text { investigation machine (side force) }\end{array}$ & Continuous & BS 7941-1 & \multirow{3}{*}{ micro-macro } \\
\hline & Grip-tester (Fixed slip) & Continuous & BS 7941-2 & \\
\hline & Norwegian Norsemeter (Variable slip) & Continuous & ASTM E1859-11 & \\
\hline $\begin{array}{l}\text { Drainage } \\
\text { (Functional - safety) }\end{array}$ & Outflow time or Permeameter & Discrete & ASTM E2380-09 & macro \\
\hline $\begin{array}{l}\text { Ride quality } \\
\text { (Functional - comfort) }\end{array}$ & Acceleration measurement & Continuous & ISO $2631-1$ & mega-unev. \\
\hline \multirow{2}{*}{ Noise (Environmental) } & Statistical Pass-By (SPB) method & Discrete & ISO $11819-1$ & macro-mega \\
\hline & Close-proximity (CPX) method & Continuous & ISO $11819-2$ & macro-mega \\
\hline Distress (Structural) & Pavement Condition Index & Continuous & ASTM D6433-11 & all \\
\hline Dynamic load (Structural) & Weigh-In-Motion & Discrete & ASTM E1318-09 & mega-unev. \\
\hline Deflection (Structural) & Falling Weight Deflectometer & Discrete & ASTM D4694-09 & not related \\
\hline
\end{tabular}

In general, many of these methods can be partially replaced by the measurement of pavement texture, in one or more appropriate range of wavelengths; pavement texture measurement methods, moreover, vary depending on the type of texture being evaluated (micro-, macro-texture, mega-texture, unevenness).

In effect, macro-, mega-texture and unevenness are currently measured with vehicle-mounted devices, that allow fast surveys and generally do not require any traffic control. Indeed, the microtexture cannot be measured directly, except in a laboratory, so it has to be indirectly estimated using low speed friction measurement devices (Wambold et al., 1995; Karamihas et al., 1999).

The vehicles for fast surveys are equipped with a height measuring sensor (laser, ultrasonic, infrared, optical), an odometer (a pulser on one of the front wheels) and an inertial reference unit (accelerometer); the system allows to collect surface elevation data at intervals of $0.25 \mathrm{~mm}$ or less for macrotexture and of $2.5 \mathrm{~cm}$ or more for megatexture and unevenness. The accuracy should be less than $0.1 \mathrm{~mm}$ for elevation data and less than $0.5 \%$ for longitudinal distance (Karamihas et al., 1999).

The pavement profile is computed from a combination of longitudinal distance, height and acceleration measurements. The height sensors used in profilometers measure 16000 times or more per second (16 kHz). It is impractical to record and use all data that is transduced by the sensors in a profiler. Thus, data are recorded into computer memory at discrete intervals relating to speed vehicle and range of texture (sample interval, $\Delta x$ ).

Profiles can be processed in different ways to obtain both synthetic and global texture measurement indexes. Table 3 provides more details on typical pavement texture/unevenness measurement indexes, their applicability and the related technical standard. 
Table 3. Indexes for the characterization of pavement texture/unevenness

\begin{tabular}{lllc}
\hline Measurement Index & Associated Standard & Type of parameter & Related Texture Pavement \\
\hline Mean profile depth (MPD) & ISO 13473-1 & Sintetic index & Macrotexture \\
International Roughness Index (IRI) & ASTM E1926-08 & Sintetic index & $\begin{array}{c}\text { Megatexture and } \\
\text { Unevenness } \\
\text { Microtexture and } \\
\text { Macrotexture }\end{array}$ \\
Surface texture (Ra) & ISO 4287 & Sintetic index & $\begin{array}{c}\text { Macro-Megatexture and } \\
\text { Unevenness } \\
\text { Texture spectrum levels }\end{array}$ \\
Simulating Vehicular Response & ISO 13473-4 & Spectral analysis & $\begin{array}{c}\text { Megatexture and } \\
\text { Unevenness }\end{array}$ \\
Simulating Truck Response & ASTM E 1170-97 & $\begin{array}{l}\text { Sintetic index and } \\
\text { Spectral analysis } \\
\text { Sintetic index and }\end{array}$ & $\begin{array}{c}\text { Megatexture and } \\
\text { Unevenness }\end{array}$ \\
\hline
\end{tabular}

In particular, the spectral analysis of road profiles (Power Spectral Density PSD and other spectra) allows to analyse simultaneously and in continuous the texture/unevenness of pavement, so characterizing the most important properties. In fact, many studies show good correlations between the intrinsic properties of the pavements (functional, environmental and structural) and the related ranges of texture/unevenness.

In the range of unevenness, some relations between PSD and the indicators of road properties are given in (Kropac \& Mucka, 2007; Sun, 2003). Other researches (Cantisani \& Loprencipe, 2010; Mucka \& Granlund, 2012) show good correlations between synthetic index of road roughness (IRI) and whole body vibration. In (Bogsjö \& Rychlik, 2009) a method for vehicle fatigue damage prediction, caused by a road with random irregularities is described. Ai and Martin (2012) have developed a new heavy vehicle roughness band index (HVRI) well correlated with PSD of road profiles. The wavelength range lying between macrotexture and unevenness is the main influencing factor of the rolling resistance (Descornet, 1990). Steinauer and Ueckermann (2002) showed that a mathematical relationship exists between PSD and dynamic wheel loads.

In the range of mega-, macro- and micro-texture, many studies (Wambold et al., 1995; Ergun et al., 2005; Flintsch et al., 2003) have shown that the friction have a good correlation with synthetic indexes of pavement macrotexture (MPD, MTD, etc.). In addition, regarding to road safety, it is demonstrated a clear relationship between pavement macrotexture and crash occurrence (Cairney \& Styles, 2005; Pulugurtha et al., 2010). Various correlations and models have been proposed in the literature between road texture and rolling noise (Descornet \& Sandberg, 1980; Hamet \& Klein, 2000; Huschek, 1996; Sandberg \& Descornet, 1980; Rasmussen et al., 2007; Domenichini et al., 1999; Losa et al., 2010).

It is possible to harmonize the characteristics of pavement texture regarding two or more performances (Descornet, 1989). Recently, Alauddin and Tighe (2008) have focused on optimizing the surface characteristics regard to safety and noise.

It may be difficult for Road Agencies, to optimize all performances of pavements; for this reason normally they refer to synthetic indexes expressing only the most important performances. It would be useful to verify all required performances at the same time, over the entire field of surface characteristics, so considering the suitability of the pavement in a global assessment.

Generally, about performance indexes, it is possible to indicate the related acceptance limits; in Table 4 some reference limits for existing roads, referred to some measurable indexes or performance parameters, are shown. 
Table 4. Examples of acceptance limits for some performance parameters (existing roads)

\begin{tabular}{|c|c|c|c|}
\hline $\begin{array}{c}\text { Measurement Index or } \\
\text { others magnitudes }\end{array}$ & $\begin{array}{c}\text { Performance } \\
\text { measured }\end{array}$ & Related Texture Pavement & $\begin{array}{c}\text { Range of values for existing } \\
\text { roads }\end{array}$ \\
\hline Mean profile depth (MPD) & Safety & $\begin{array}{l}\text { Macrotexture and } \\
\text { Megatexture }\end{array}$ & $0.5-1.5[\mathrm{~mm}]$ \\
\hline International Roughness Index (IRI) & Comfort & $\begin{array}{l}\text { Megatexture and } \\
\text { Unevenness }\end{array}$ & $2.0-4.0[\mathrm{~m} / \mathrm{km}]$ \\
\hline British Pendoloum Number & Safety & Microtexture & 50-70 [unitless] \\
\hline Side Force Coefficient (SFC) & Safety & $\begin{array}{l}\text { Microtexture and } \\
\text { Macrotexture }\end{array}$ & $0.40-0.50$ [unitless] \\
\hline Dynamic Truck Axle Load & Structural & $\begin{array}{l}\text { Megatexture and } \\
\text { Unevenness }\end{array}$ & $\begin{array}{l}\text { no standard value (only } \\
\text { empirical indexes) }\end{array}$ \\
\hline Noise spectrum optimal levels ( $\mathrm{L}^{\mathrm{opt}}$ ) & Environmental & $\begin{array}{l}\text { Macrotexture and } \\
\text { Megatexture }\end{array}$ & $\mathrm{L}^{\mathrm{opt}}=\mathrm{L}(\mathrm{f})[\mathrm{dB}]$ or $[\mu \mathrm{m}]$ \\
\hline
\end{tabular}

It is important to highlight that some parameters are expressed by means of numerical and standardized indexes related to pavement texture; on the other hand, considering other properties or performances (noise and structural properties), standardized indexes are not established and it is necessary to use literature correlations to assess the corresponding acceptance limits.

\section{Methods for Pavement Profiles Analysis}

Current measurements and surveys techniques allow to obtain a detailed texture characterization that can be used to define the requirements for design, construction and management of the road pavement. However, it seems necessary to propose a new procedure for the analysis and evaluation of data coming from surveys. The proposal presented in this paper consists in an unified analysis, over the entire range of wavelengths (or frequencies) having practical interest, of the data representing road profiles; in this way, it will be possible to establish the acceptability field of the parameters, referred to an unique indicator that represents the texture level.

In particular, the suggested indicator consists in an expression of the texture referred to its amplitudes respect to spatial frequencies. In fact, although the representation in the space domain would be the most natural expression for a road pavement profile, it appears more interesting to analyse the profiles in the domain of spatial frequencies, so representing them as a sum of sinusoidal waves; this kind of treatment is named "generalized harmonic analysis".

Starting from the measure of road profiles, obtained with the use of a constant sampling step, it is possible to decompose them in sinusoidal waves. The texture, indeed, can be considered as a random wave-like phenomenon, and therefore it is possible to obtain, for it, the discrete function of Power Spectral Density (PSD) of amplitudes (Thompson, 1958; Ahmadi \& Salami, 2010; Li et al., 2009).

The Technical Specification ISO 13473-4 defines the methods that should be used to implement a spectral analysis of pavement surface, starting from measured profiles. The result of the frequency analysis is a texture spectrum, usually expressed in one-third-octave bandwidth (or in another fractional-octave-band).

This Technical Specification offers three alternative methods to obtain the spectra; the third method offers greater flexibility in choosing analysis parameters and uses a constant narrow bandwidth frequency analysis by means of Discrete Fourier Transform (DFT), followed by a transformation of the narrow-band spectrum to an octave- or one-third-octave-band spectrum, so obtaining the spectrum of texture level.

In this paper the third method has been implemented to characterize the texture of test pavements, starting to their measured profiles. In Figure 3 the flow chart of applied method is shown. 


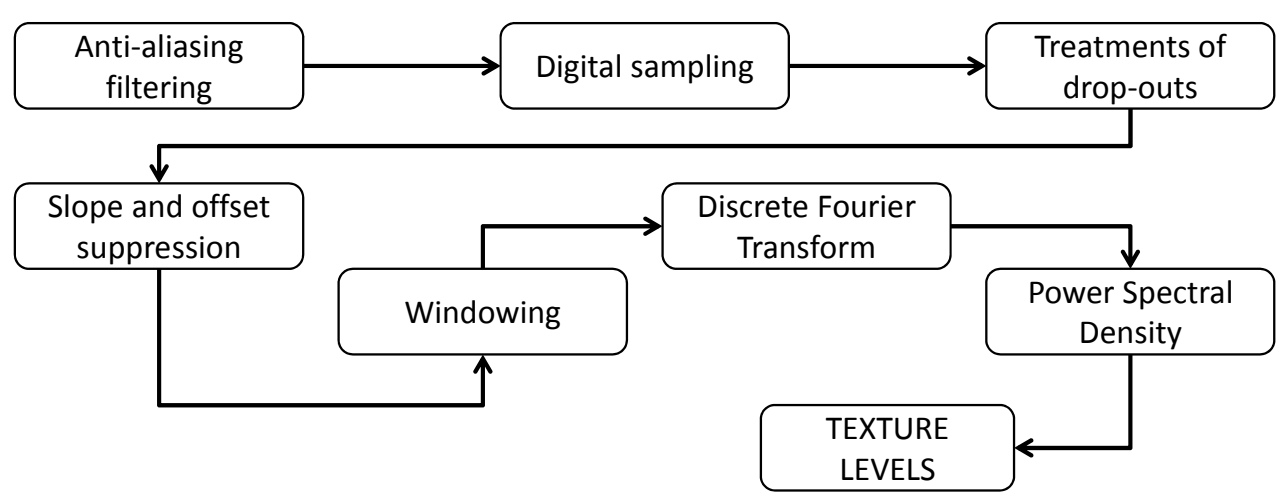

Figure 3. Flow chart to calculate the amplitude texture levels starting from measured profile

The following processes are necessary:

Anti-aliasing filtering: this filter is first used on a special signal sampler of profile, to restrict the bandwidth of a signal in order to approximately satisfy the Nyquist-Shannon sampling theorem.

Digital sampling: the measured pavement profiles are performed at spatial sampling intervals $\Delta \mathrm{x}$ that are determined according to ISO 13473-3 for the shortest wavelength involved in the spectral analysis. For each range of texture the shortest wavelength is different, therefore the profilometers should be able to perform different spatial sampling intervals $\Delta \mathrm{x}\left(\Delta \mathrm{x}_{\text {macro }}, \Delta \mathrm{x}_{\text {mega }}, \Delta \mathrm{x}_{\text {unev }}\right)$.

Treatments of drop-outs: in consequence to local operating conditions of height measuring sensor, some measure are invalid; for a pavement profile, if the drop-out rate is not more than $10 \%$ then a linear interpolation may be used to replace the invalid samples.

Slope and offset suppression: in consequence to operating principle of each profiler, the samples are referred to a relative reference and normally in the pavement may be present some section with longitudinal slope. If the $Z_{n}(x)$ is the native measurement profile is necessary to obtain a profile $Z(x)$ for which both mean level and longitudinal slope of the profile have to be brought to zero.

Windowing: to perform the spectral analysis should be applied to profile a Fourier Transform, for continuous signal, that may be applied also to a sampling discrete signal (Discrete Fourier Transform). This analysis is based on the assumption that the input discrete signal repeats itself with a period equal to the signal duration. The singles signals may be linked only if at the edges of each discrete signal there are the same values equal to zero. The windowing reduces the signal to zero at the edges limiting the attenuation of the signal out of the edges. The general equation for determining the windowed profile $Z_{i, \text { win }}$ starting to original profile $Z_{i}$ is given in Equation (1)

$$
Z_{i, \text { win }}=\frac{w_{i} Z_{i}}{\sqrt{\frac{1}{N} \sum_{i=0}^{N-1} w_{i}^{2}}} \quad \text { for } i=0,1, \ldots, N-1
$$

where $w_{i}$ is a set of coefficients that change the original profile to reduce this effect known as "leakage".

Discrete Fourier Transform (DFT): The DFT takes a vector of $\mathrm{N}$ complex (or real) numbers $Z_{i}, i=0,1, \ldots,(\mathrm{N}-1)$ and transforms it into a vector of $\mathrm{N}$ complex numbers $Z_{k}, k=0,1, \ldots,(\mathrm{N}-1)$.

$$
Z_{k}=\frac{1}{N} \sum_{i=0}^{N-1} Z_{i} \cdot e^{-j\left(\frac{2 \pi k}{N}\right)^{i}} \text { where } \mathrm{j} \text { is the imaginary unit } \mathrm{j}^{2}=-1
$$

In general, for the time series of signal, DFT realizes a transformation from the time domain $(s)$ to the frequency domain $(H z, 1 / s)$. In the case of road profiles the digitized input signal is always real and there isn't a time series but a measured distance. Therefore, for the road profile DFT involves a transformation from the distance domain (in $\mathrm{m}$ ) to the spatial frequency domain (in cycle/m or $1 / \lambda$ where $\lambda$ is the wavelength).

The result of the DFT is a constant bandwidth narrow band spectrum $\Delta f$ with complex values. The bandwidth $\Delta f$ depends on the discrete profile length $L=(\mathrm{N}-1)^{*} \Delta x$ and is equal to: 


$$
\Delta f=1 / L
$$

To ensure that $Z_{k}$ is independent on the length $L$ of the discrete signal, it is necessary to use a window function (windowing). For this reason, the $Z_{i}$ in Equation (2) should be a windowed signal $\left(Z_{i, w i n}\right)$.

The spatial frequency scale of $Z_{k}$ starts at 0 with steps equal to $\Delta f$ until $f_{\max }=(N / 2-1) \Delta f$. The others $Z_{k}$ complex values shall be not used because this function is symmetrical (double sided).

Power Spectral Density: The PSD is a measure in the frequency domain of the power (squared amplitude) contained in a signal per unit frequency and it is expressed in $\mathrm{m}^{2} / \mathrm{m}^{-1}=\mathrm{m}^{3}$ or in $\mathrm{mm}^{3}$. PSD is obtained by dividing the squared amplitude of each narrow band by the spectral bandwidth $\Delta f$ according to equation

$$
Z_{k}^{P S D}=\frac{2 \cdot\left|Z_{k}\right|^{2}}{\Delta f} \text { for } k=0,1, \ldots,\left(\frac{N}{2}-1\right)
$$

The result is a constant bandwidth spectrum; we can use different $\Delta f$ one for each considered range; for example, for unevenness range, we can adopt $\Delta f_{\text {unev }}=1 / L_{\text {unev }}=1 / 100=0.01 \mathrm{c} / \mathrm{m}$ where $L_{\text {unev }}=100 \mathrm{~m}$ is the evaluation length of pavement profiles useful to evaluate a wavelength in one-third-octave bands spectral analysis $\lambda_{\text {max, unev }}$ $=6.7 \mathrm{~m}$; for macrotexture range, we can adopt $\Delta f_{\text {macro }}=1 / L_{\text {macro }}=1 / 1=1 \mathrm{c} / \mathrm{m}$ where $L_{\text {macro }}=1 \mathrm{~m}$ is the evaluation length of pavement profiles useful to evaluate a wavelength in one-third-octave bands spectral analysis $\lambda_{\text {max } \text {,macro }}=0.067 \mathrm{~m}$.

Further processing of the PSD is possible; the table shows others ways to express the spectral texture unit.

Table 5. Spectral texture units

\begin{tabular}{llll}
\hline Abbrev. & Name & Relation & Unit \\
\hline PSD & Power Spectral Density & & $\mathrm{m}^{2} / \mathrm{m}^{-1}=\mathrm{m}^{3}$ \\
PS & Power Spectrum & $P S=P S D \cdot \Delta f$ & $\mathrm{~m}^{2}$ \\
ASD & Amplitude Spectral Density & $A S D=\sqrt{P S D}$ & $\mathrm{~m} / \mathrm{m}^{-0.5}=\mathrm{m}^{1.5}$ \\
AS & Amplitude Spectrum & $A S=\sqrt{P S}$ & $\mu \mathrm{m}$ \\
& Texture Profile Level in dB & $L_{T X}=20 \cdot \log _{10}\left(\frac{A S}{10^{-6}}\right)$ & $\mathrm{dB}$ \\
\hline
\end{tabular}

The transformation of a constant bandwidth spectrum to a constant-percentage bandwidth spectrum can be made using the procedure proposed by ISO8608.

\section{A Proposal for an Optimized Area for Road Performances}

In previous sections, it was established that texture and unevenness properties can be effective to represent a road pavement, with reference to various performances, both for the acceptance of new road works and to decide when it is necessary to plan some maintenance interventions. The texture characteristics are really suitable because they are reliable (respect to possible environmental and local factors that can alter the measurements of real road conditions), easy to determine and clear to identify.

However, as previously said, some interaction phenomena are affected in an opposite way by the level of texture, in the same wavelengths domain. A significant example is given by friction and rolling noise: in the macrotexture domain (wavelengths from $0.5 \mathrm{~mm}$ to $50 \mathrm{~mm}$, spatial frequencies from $2000 \mathrm{c} / \mathrm{m}$ to $20 \mathrm{c} / \mathrm{m}$ ) an increase of the macrotexture determines better performances of the road surface respect to the friction, especially in wet conditions and for vehicles' high speeds, but, on the other hand, it also produces an higher noise level. For this reason, with the aim to optimize the performances of the road pavement in the macrotexture domain, it is possible to set an interval of values for the selected texture indicator (in particular, the texture level): the lower limit of the interval will be related to the friction performance, the upper one will be decided according to the purpose to generate an acceptable rolling noise.

If we generalize the above proposed criteria, an "optimized area" can be defined, in the graph representing frequency vs. texture level (see Figure 4); this area defines a field where the spectrum of a pavement texture has to fit into, to ensure an adequate behaviour respect all the performances related to tyres-pavement interactions. If the texture index overpasses the boundary of the area, some adjustments will be necessary to restore the optimal conditions. 


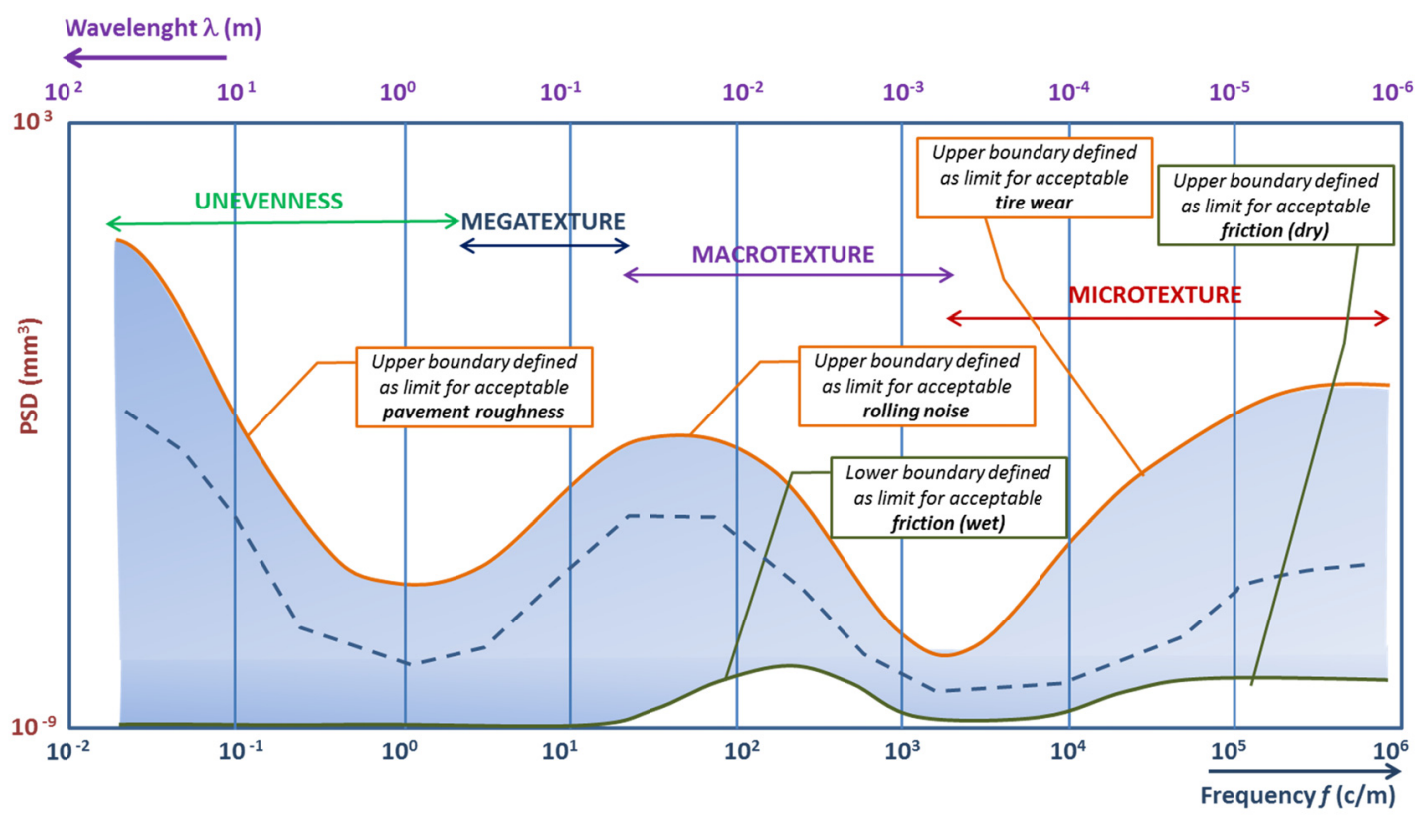

Figure 4. Proposal of an "optimized area" for a texture index, in reference to road performances

The definition of the optimized area can be obtained if the threshold limits, for each domain, are established. These limits can be determined on the basis of correlations available in the scientific literature, deduced from empirical researches or established according to a judgemental decision, also considering the specific characteristics of the road network and the level of needed performances.

\section{Case Study}

The described methods has been applied to 11 different road pavements, whose surface characteristics were investigated respect to texture/unevenness properties and noise emission during the UE research project entitled TINO (Measuring Understanding and Reducing Tire Noise Emission Under Realistic Vehicle Operating Conditions Including the Contribution of the Road Surface-BRITE EURAM project no. 1552); the research program, in fact, included experimental activities (both in situ and in laboratory) and data analysis (Domenichini, et al., 1999).

The performed texture measurements were: microtexture measurement (by means of the British Portable Pendulum), macrotexture measurement (by means of both stationary profilometer and volumetric method), megatexture and unevenness measurements (by means of a walking profilometer). So, the pavement texture/unevenness was evaluated in terms of:

- Synthetic Indexes of Profiles (MPD, according to ISO 13473-1, for macrotexture and IRI, according to ASTM E1926-08, for megatexture and unevenness).

- Spectral Analysis of Profiles (Amplitude spectrum according to ISO 13473-4 and ISO 8608 for macro-, mega-texture and unevenness).

The noise measurements included: Coast-By (CB) method and Close-Proximity (CPX) method. For each test the noise spectra in the frequency domain in one-twelfth octave bands were obtained.

The performed measurements allowed to thoroughly investigate the relationships between rolling noise and pavement texture, evaluating for each frequency of emitted noise the specific contribution of all the texture wavelengths (or spatial frequencies); the results allowed to realize, in particular, a pavement specifically defined with the aim to produce low rolling noise.

Starting from these profiles and considering their characteristics, expressed by synthetic indexes, and the relative spectral analyses, the correlations between these indexes and the texture level for all spatial frequencies were obtained; the intervals where the best correlations are achieved were so individuated (Figure 5). 


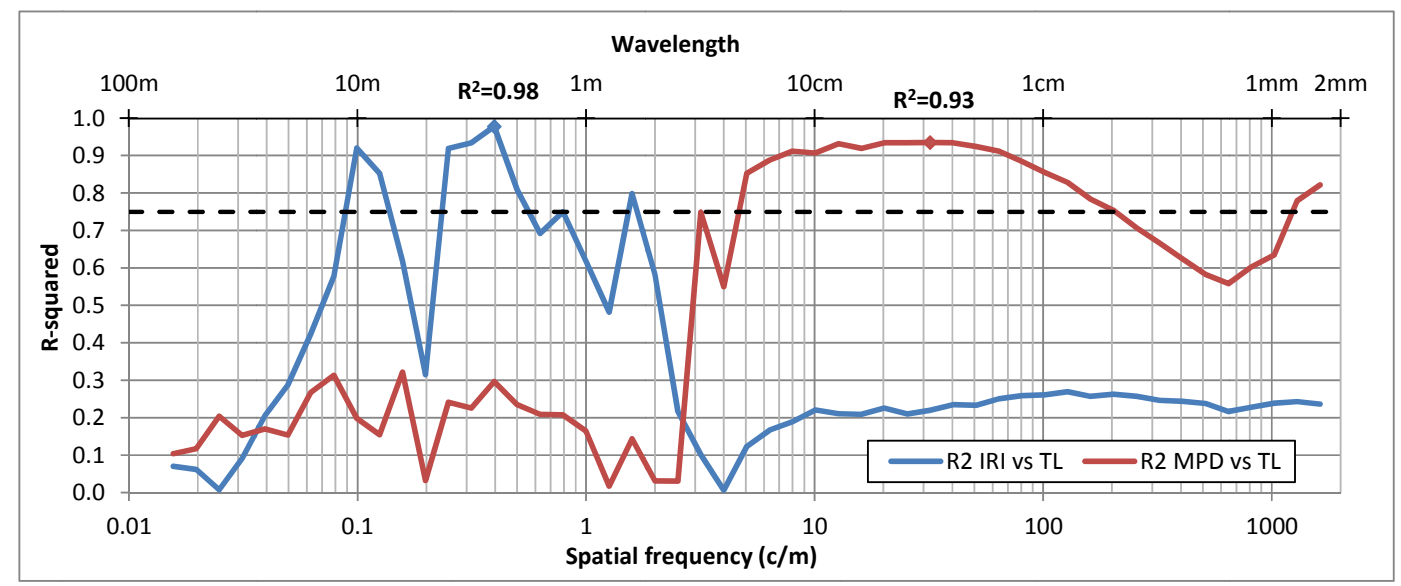

Figure 5. Correlation between texture level and synthetic indexes

The comparison of texture synthetic indexes (IRI and MPD) and those obtained from spectral analysis (PSD of amplitudes) shows good agreement (with a regression coefficient of $\mathrm{R}^{2}$ greater than 0.75 , see Figure 6 ) only for the wavelength ranges that typically influence the synthetic index. Thus, the IRI shows good agreement with the amplitude in the unevenness wavelengths $(0.6 \mathrm{~m}, 1.3-4 \mathrm{~m}$ and 6-11 $\mathrm{m})$ and the MPD shows good agreement with the amplitude in the mega and macro wavelengths (from $5 \mathrm{~mm}$ to $10 \mathrm{~cm}$ ). The figure shows that the best regression for IRI and MPD are achieved respectively for texture wavelength equal to $2.5 \mathrm{~m}$ and $3 \mathrm{~cm}$.
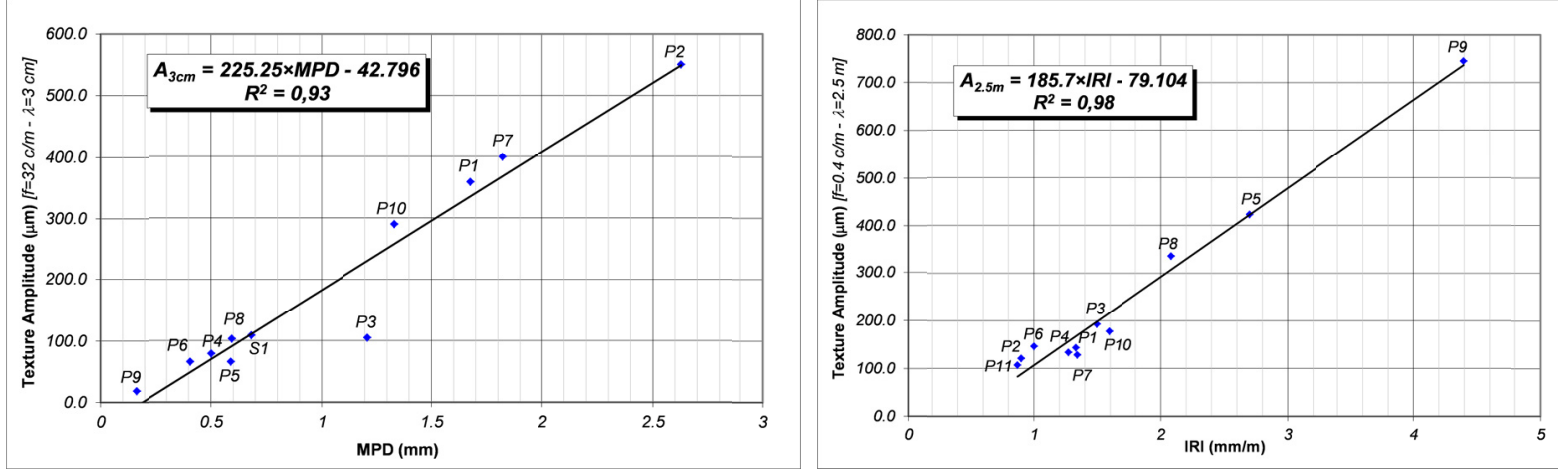

Figure 6. Correlations between MPD/IRI and Texture Amplitude

In the ranges where a good agreement was found, the fit curves were calculated for each wavelength; so, it is possible to estimate the spectral amplitudes related to accepted values of IRI and MPD. For the rolling noise the evaluation is more complex because it is necessary to use some experimental results (coming from TINO project and other researches), in terms of correlations between generated noise levels and texture levels, to establish the limits for the texture amplitudes, in order to contain the emitted noise.

Recently, an empirical rolling noise prediction model based on pavement surface characteristics, was developed (Losa et al., 2010); the model defines an ideal texture spectrum, for various vehicular speed $(100 \mathrm{~km} / \mathrm{h}, 50 \mathrm{~km} / \mathrm{h}$ ), that reduces the rolling noise. The texture spectrum referred to $50 \mathrm{~km} / \mathrm{h}$, for example, could be used to establish the upper limit of optimized area for the texture of pavements in urban area, where the speed are low and the reduction of noise is very important. 


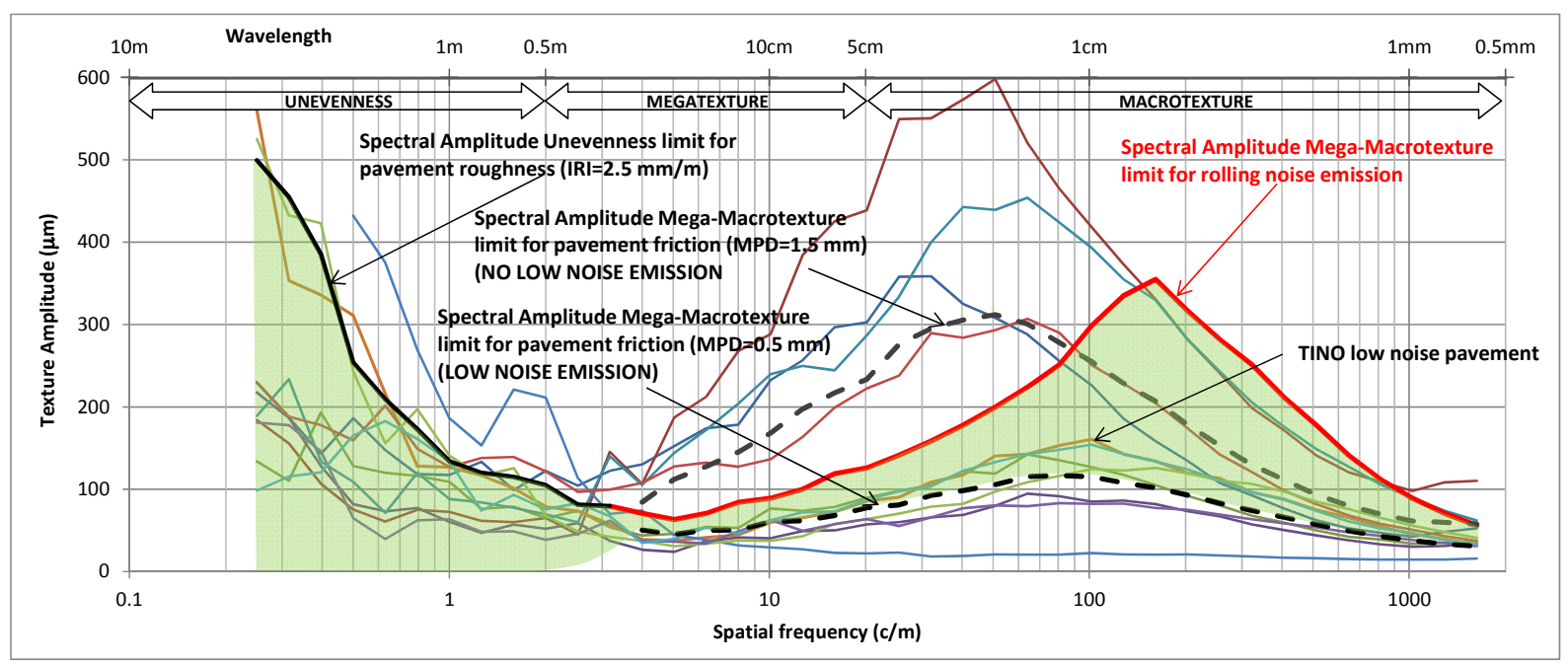

Figure 7. Verification of acceptance limits for the pavements considered as case study

If we draw in a graph representing frequency vs. texture level the limits of the optimized area (both for low noise pavements and normal pavements) and the spectra of the 11 pavements, considered as a case study Figure 7, we can see that some surfaces fit into and other overpass the boundaries of the area; this condition means that some pavements can be accepted respect to the established limits of performance parameters and the other ones are not acceptable. In particular, as expected, the low noise pavements defined in the TINO research project satisfy the requirements for all the wavelengths considered ranges.

\section{Conclusions}

The geometry of road surfaces, that can be expressed in terms of texture or unevenness, is related to many characteristics and performances of pavements. The effects regard the safety of road exercise (friction, drainage, dynamic control of vehicle), the structural properties of the infrastructure (distress and deflection of pavement, dynamic load), the functionality and the efficiency of the entire system (comfort, fuel consumption, wearing of tyres, emissions, pollutions, ...) also with regard to the natural environment.

The interaction phenomena also depend on the domain of irregularities of road surface (unevenness, mega-, macro- and micro-texture). In particular, there are some conflicting effects, for which a greater or lesser level of texture can result in a better or worse performance of the pavement.

The availability of modern measurement techniques and advanced devices allows to acquire in continuous the data needed for the geometric characterization of pavements; also the costs, in terms of time and equipment, is relatively limited and there are few interferences with the normal exercise. Therefore, it seems useful to introduce some comprehensive methods for the analysis and evaluation of the acquired data, according, moreover, to previous studies and researches that propose synthetic representations or indicators for the performances of road surfaces (Alauddin \& Tighe, 2008). In particular, the analysis of the content in terms of spatial frequency of the profiles, measured on the pavement, may allow to determine the PSD function of the amplitudes and the deriving variables (the RMS of amplitudes or, more frequently, the level of texture), in the entire range of frequencies (or wavelengths) which has a practical interest.

So, it is possible to obtain a spectrum of texture, characteristic for each pavement, which effectively represents the surface geometry. This spectrum can be compared to an optimized area; if it fit into the area, the pavement achieves a good compromise between all the functional requirements, instead, if the pavement overpasses the boundary, it is necessary to plan some maintenance or rebuilding works. The limits of this optimized area can be established on the basis of correlations between road performances and texture, coming from the literature or according to decision criteria that can consider the specific characteristics of road infrastructures.

Referring to this last consideration, it is important to observe that the proposed methodology can result very useful for road Agencies or Companies which supervise on road networks, because they can decide the functional requirements according to technical and strategic role of the infrastructures (i.e., differentiating the optimization limits for freeways or highways respect to rural roads) and taking into account the expectation of users that are interested in. It would be possible to decide both the technical standards to ensure for new constructions or for the acceptance of re-paving works and to define the criteria to plan the maintenance 
activities, required when a pavement loses its properties, as a result of wearing due to traffic and environmental factors.

The unified method for analysis and evaluation of road surfaces, proposed in this article, may therefore be useful for current technical practices and to improve the efficiency and effectiveness of the actions, performed by both professional engineers and road Administrations.

\section{References}

Ahmadi, H., \& Salami, P. (2010). Using of Power Spectral Density for Condition Monitoring of Fan. Modern Applied Science, 4(6), 54-59.

Ai, U., \& Martin, T. (2012). The development of a heavy vehicle roughness band index (HVRBI). Perth, Australia, 25th ARRB Conference.

Alauddin, M., \& Tighe, S. (2008). Incorporation of Surface Texture, Skid Resistance and Noise into PMS. Calgary, Canada, 7th International Conference on Managing Pavement Assets (icmpa2008), pp. 1-11.

ASTM/E1170-97. (2012). Practices for Simulating Vehicular Response to Longitudinal Profiles of Traveled Surfaces. E17 Committee West Conshohocken, USA: ASTM International.

ASTM/E1845-09. (2009). Practice for Calculating Pavement Macrotexture Mean Profile Depth. E17 Committee West Conshohocken, USA: ASTM International.

ASTM/E1926-08. (2008). Practice for Computing International Roughness Index of Roads from Longitudinal Profile Measurements. E17 Committee West Conshohocken, USA: ASTM International.

ASTM/E2034-99. (2012). Practices for Simulating Truck Response to Longitudinal Profiles of Vehicular Traveled Surfaces. E17 Committee West Conshohocken, USA: ASTM International.

ASTM/E303-93. (2008). Test Method for Measuring Surface Frictional Properties Using the British Pendulum Tester. E17 Committee West Conshohocken, USA: ASTM International.

ASTM/E965. (1996). Test Method for Measuring Surface Macrotexture Depth Using a Volumetric Technique. E17 Committee West Conshohocken, USA: ASTM International.

Baran, R., \& Henry, J. (1983). Tire Noise and Its Relation to Pavement Friction. Transportation Research Record, No. 946, 00389581(HS-037 873), pp. 44-48.

Bitelli, G., Simone, A., Girardi, F., \& Lantieri, C. (2012). Laser Scanning on Road Pavements: A New Approach for Characterizing Surface Texture. Sensors, 12(12), 9110-9128.

Bogsjö, K., \& Rychlik, I. (2009). Vehicle fatigue damage caused by road irregularities. Fatigue \& Fracture of Engineering Materials \& Structures, 32(5), 391-402.

Cairney, P., \& Styles, E. (2005). A pilot study of the relationship between macrotexture and crash occurrence, Victoria, Australia: Australian Transport Safety Bureau.

Cantisani, G., \& Loprencipe, G. (2010). Road roughness and whole body vibration: Evaluation tools and comfort limits. Journal of Transportation Engineering, 136(9), 818-826.

Davis, R. (2001). Comparison of Surface Characteristics of Hot-Mix Asphalt Pavement Surfaces at the Virginia Smart Roads. PhD Thesis-Master of Science in Civil and Environmental Engineering. http://scholar.lib.vt.edu/theses/available/etd-07262001-193459/ Blacksburg, Virginia, USA.: Virginia Polytechnic Institute and State University.

Descornet, G. (1989). A criterion for optimizing surface characteristics. Transportation Research Record, 1215, 173-177.

Descornet, G. (1990). Road-surface influence on tire rolling resistance. Surface characteristics of roadways: International research and technologies, ASTM-STP, 1031, 401-415.

Descornet, G., \& Sandberg, U. (1980). Road Surface Influence on Tire/Road Noise- Part I. Miami, Florida, s.n., pp. 259-266.

Domenichini, L., Fracassa, A., Torre, F. L., Loprencipe, G., Scalamandrè, A., \& Ranzo, A. (1999). Relationship between road surface characteristics and noise emission. Roma, Italy, TINO First International Colloquium on Vehicle Tyre Road Interaction.

Ergun, M., Iyinam, S., \& Iyinam, A. (2005). Prediction of road surface friction coefficient using only macro-and microtexture measurements. Journal of transportation engineering, 131(4), 311-319. 
Flintsch, G., de León, E., McGhee, K., \& AI-Qadi, I. (2003). Pavement surface macrotexture measurement and applications. Transportation Research Record: Journal of the Transportation Research Board, 1860(1), 168-177.

Flintsch, G., McGhee, K., de León Izeppi, E., \& Najafi, S. (2012). The Little Book of Tire Pavement Friction. USA. $\quad$ Retrieved from http://www.vtti.vt.edu/1-Pagers\%20for\%20Website/CSTI_Flintsch/The\%20Little\%20Book\%20of\%20Tire $\% 20$ Pavement $\% 20$ Friction.pdf

Hall, J. et al. (2009). Guide for Pavement Friction, Washington D.C. USA.: National Cooperative Highway Research Program. Retrieved from http://onlinepubs.trb.org/onlinepubs/nchrp/nchrp_w108.pdf

Hamet, J. F., \& Klein, P. (2000). Road texture and tire noise. Proc. inter noise, pp. 178-183. Retrieved from http://inrets.fr/ur/lte/publications/publications-pdf/web-hamet/in00_674.pdf

Henry, J., \& Dahir, S. (1979). Effects of Textures and the Aggregates that Produce Them on the Performance of Bituminous Surfaces. Transportation Research Record, No. 712, pp. 44-50.

Hibbs , B., \& Larson, R. (1996). Tire Pavement Noise and Safety Performance. Washington D.C., USA.: FHWA, U.S. Department of Transportation.

Huschek, S. (1996). Characterization of pavement surface texture and its influence on tire/road noise. Christchurch, New Zealand, s.n.

ISO13473-1:2004. (2004). Characterization of pavement texture by use of surface profiles - Part 1: Determination of Mean Profile Depth. Geneva, Switzerland: International Organization for Standardization.

ISO13473-2:2002. (2002). Characterization of pavement texture by use of surface profiles - Part 2: Terminology and basic requirements related to pavement texture profile analysis. ISO/TC43/SC1 Geneve, Switzerland: Multiple. Distributed through American National Standards Institute ANSI.

ISO13473-3:2002. (2002). Characterization of pavement texture by use of surface profiles - Part 3: Specification and classification of profilometers. ISO/TC43/SC1 Geneve, Switzerland: Multiple. Distributed through American National Standards Institute ANSI.

ISO13473-4:2008. (2008). Characterization of pavement texture by use of surface profiles-Part 4: Spectral analysis of surface profiles. ISO/TC43/SC1 Geneve, Switzerland: Multiple. Distributed through American National Standards Institute ANSI.

ISO2631-1:1997. (1997). Mechanical vibration and shock-Evaluation of human exposure to whole-body vibration - Part 1: General requirements. ISO/TC108/SC4 Geneve, Switzerland: Multiple. Distributed through American National Standards Institute ANSI.

ISO8608:1995. (1995). Mechanical vibration-Road surface profiles-Reporting of measured data. ISO/TC108/SC2 Geneve, Switzerland: Multiple. Distributed through American National Standards Institute (ANSI).

Karamihas, S., Gillespie, T., Perera, R., \& Kohn, S. (1999). Guidelines for longitudinal pavement profile measurement. NCHRP Project 10-47 USA: University of MichiganTransportation Research Institute.

Kropac, O., \& Mucka, P. (2007). Indicators of longitudinal road unevenness and their mutual relationships. Road Materials and Pavement Design, 8(3), 523-549.

Li, J., Chen, L., \& Cai, Y. (2009). Dynamic Texture Segmentation Using Fourier Transform. Modern Applied Science, 3(9), 29-36.

Losa, M., Leandri, P., \& Bacci, R. (2010). Empirical Rolling Noise Prediction Models Based on Pavement Surface Characteristics. Road Materials and Pavement Design, 11(sup1), 487-506.

Mucka, P., \& Granlund, J. (2012). Is the Road Quality Still Better? Journal of Transportation Engineering, $138(12), 1520-1529$.

Papoulis, A., \& Pillai, S. (2001). Probability, Random Variables, and Stochastic Processes. s.1.: McGraw-Hill Science Engineering.

PIARC. (1987). World Road Association: Report of the Committee on Surface Characteristics. Brussels, Belgium, s.n.

Pulugurtha, S., Kusam, P., \& Patel, K. (2010). Assessing the role of pavement macrotexture in preventing crashes on highways. Traffic injury prevention, 11(1), 96-103. 
Rasmussen, R., Bernhard, R., Sandberg, U., \& Mun, E. (2007). The Little Book of Quieter Pavements, Washington D.C., USA: USDOT, Federal Highway Administration.

Sandberg, U., \& Descornet, G. (1980). Road Surface Influence on \{Tire/Road\} Noise- Part I. Miami, Florida, s.n., pp. 267-272.

Sayers, M., \& Karamihas, S. (1998). The Little Book of Profiling. Retrieved from www.umtri.umich.edu/content/LittleBook98R.pdf

Steinauer, B., \& Ueckermann, A. (2002). Road roughness and its effects on the infrastructure. Delft, The Netherlands, 7th International Symposium on Heavy Vehicle Weights \& Dimensions.

Stroup-Gardiner, M., Studdard, B., \& Wagner, C. (2001). Influence of Hot Mix Asphalt Macrotexture on Skid Resistance. Auburn, AL, USA.: Auburn University.

Sun, L. (2003). Simulation of pavement roughness and IRI based on power spectral density. Mathematics and Computers in Simulation, 61(2), 77-88.

Thompson, W. (1958). Measurements and power spectra of runway roughness at airports in countries of the North Atlantic Treaty Organization. Washington D.C., USA.: National Advisory Committee for Aeronautics.

Wambold, J. C., \& Henry, J. J. (1995). International PIARC Experiment to Compare and Harmonize Skid Resistance and Texture Measurements. PIARC Publication, Issue 01.

\section{Copyrights}

Copyright for this article is retained by the author(s), with first publication rights granted to the journal.

This is an open-access article distributed under the terms and conditions of the Creative Commons Attribution license (http://creativecommons.org/licenses/by/3.0/). 